\title{
Theory and Practice of the Mini-bibliobattle as an Output Activity of Extensive Reading
}

\author{
Kazuma Fujii \\ Foreign Languages and Humanities Group, Nagaoka University of Technology, Niigata, Japan
}

\begin{abstract}
The purposes of the present paper are (a) to propose the Mini-Bibliobattle as an appropriate output activity linked with the extensive reading (ER) program by discussing its theoretical background and (b) to explore the effects of the Mini-Bibliobattle on the change of reading attitudes through one case study. The current paper firstly reviews the previous literature on the outcome of ER and points out that little study has been done concerning how the input of English gained through ER can efficiently be connected to the development of the output ability. In this paper, the Mini-Bibliobattle, in which each participant makes a three-minute presentation on his/her favorite book, answers the questions by the audience, and decides a champion book, was proposed as an appropriate output activities of ER. Then its rationale was discussed from the two perspectives, i.e., continuity with ER and relatedness to ER. Additionally, a case study was conducted with 46 third-year technical college students to investigate the effects on their reading attitudes. This case study found that (a) the participants came to read English more carefully than before (b) they came to expand the range of book selection and (c) most participants recognized that the Mini-Bibliobattle was a meaningful activity for their output ability development.
\end{abstract}

Index Terms —extensive reading, Mini-bibliobattle, output activity, reading attitudes

\section{INTRODUCTION}

Extensive Reading (ER) is defined as reading that exposes learners to large quantities of material within their linguistic competence (Grabe \& Stoller, 2002). In the ER course, learners have a choice in what they read, and the purpose of reading is usually related to pleasure, information, and general understanding (Nation \& Waring, 2013). ER has been a major form of language input for those who study English as a Foreign Language (EFL), who rarely have an opportunity to use the language outside the classroom (Nation, 2011; Takase, 2012). It is also argued in cognitive science that multiple encounters through listening and reading are indispensable to language development under the EFL circumstances (Nakamori, 2013). With the urgent need to find a way of increasing comprehensible input, the influence of ER on English education in Japan began to spread at the beginning of the 21st century. Sakai (2002) proposed one million words as a milestone and outlined the three basic ER principles for Japanese learners of English: (a) Read what you can enjoy without a dictionary. (b) Skip the words you do not understand. (c) Read books of interest. In other words, learners are encouraged to read a book like the way they usually read in their native language. By starting with very simple books, they can enjoy reading English without being interfered by repeated use of dictionaries. By having an experience of reading a whole foreign book on their own, they can build up confidence and feel pleasure in reading English. These experiences motivate learners to read more, leading to a massive amount of authentic language exposure. As a result, their English ability is expected to be developed gradually and steadily.

The ER approach to language learning with the three principles made an impact on many EFL classrooms in Japan, where the traditional grammar-translation method has dominantly been used. The approach of reading lots of simple English without dictionaries seemed new to learners as well as teachers who were used to translating English into Japanese word by word with dictionaries or taking the search-translation-equivalent strategy (Tanaka \& Abe, 1984) while reading. After the first proposal of the three principles of ER by Sakai (2002), Furukawa and Kawade (2003) published an introductory book while mentioning the effectiveness of ER. Sakai and Kanda (2005) suggested a detailed methodology of conducting SSR (Sustained Silent Reading) programs at schools. Furukawa (2010) explained how he had managed his ER class while displaying its effectiveness on junior and senior high school students at his English school. Takase (2010) published a teaching manual for extensive reading and extensive listening targeting English teachers in Japan. All of them stressed the importance of the amount to be read along with the easiness of the English texts as the means of comprehensible input (Nishizawa, Yoshioka, \& Ichikawa, 2017). Thus more and more schools have adopted the ER program every year in Japan (Takase, 2010).

In addition to these works which focus on how to organize the ER course, the number of empirical studies and practice reports which display and discuss the effectiveness of ER has been increasing. These studies and reports have contributed to elaborating the ER methodology and boosting the presence of ER. For example, Nishizawa, Yoshioka, and Fukada (2010) implemented the four-year or six-year (if included the advanced course at their college) long ER program and had enthusiastically kept encouraging their students to read extensively not only in class but also outside of class. As a result, about half of their students read more than one million words in total before graduation every year. 
The effectiveness of their ER program has been displayed in the significant TOEIC ${ }^{R}$ (Test of English for International Communication) score increase. Some of their students had read more than three million words in total, and this number is regarded as a threshold to reach the level of students who had studied abroad for one year in terms of the TOEIC ${ }^{R}$ test score (Nishizawa, 2010). Since these studies showed the benefits of ER quantitatively, at least some of the Japanese teachers who had been skeptical about the benefits of ER altered the current teaching practices. Thus the increasing number of educational institutions in Japan have begun employing the ER program to get over the input-poor problem.

However, while many studies have put emphasis on the strength of ER in increasing language exposure, only a few attempts have so far been made as to how the input of English gained through ER can be connected to the improvement of the output (i.e., speaking and writing) ability under the EFL circumstances or what activity can be considered appropriate for those who have experienced ER. Although some examples of reading activities are listed in Bamford and Day (2004) and Nakanishi (2005), the number is still limited for English learners at the elementary level in the EFL context. The present paper focuses on this issue and proposes the Mini-Bibliobattle as one of the appropriate and feasible output activities of ER, discussing its rationale. Furthermore, a case study was conducted with 46 third-year technical college students to investigate the effects of the Mini-Bibliobattle on the reading attitudes. Thus, the pedagogical appropriateness of the Mini-Bibliobattle as an output activity of ER is discussed through theory and practice.

\section{Previous Research}

A substantial number of previous studies have examined the effects of ER on the development of English proficiency, reading attitudes and the learners' affection. The preceding literature has indicated the effectiveness of ER in such fields as reading fluency (Beglar \& Hunt, 2014; Fujii, 2017a; Fujita \& Noro, 2009; Imamura, 2008; Iwahori, 2008), learners' positive attitudes or affection for reading English (Fujii, 2013; Nation, 1997; Robb \& Susser, 1989; Takase, 2012), vocabulary building (Day \& Bamford, 1998; Horst, 2005; Kweon \& Kim, 2008; Krashen, 2004; Pitts, White \& Krashen, 1989; Waring \& Takaki, 2003), and the English proficiency improvement in terms of the standardized proficiency test score (Furukawa, 2010; Nishizawa et al., 2010; Nishizawa et al., 2017). Green (2005) includes critical thinking skills and the appreciation of different authorial viewpoints as the benefits of ER. It has been pointed out that these effects become more prominent by conducting the long-term continuous ER program (Krashen, 2004; Nishizawa et al., 2017) and by reading more than 100,000 total words (Takase, 2010) in the EFL context like Japan.

A closer look at the literature, however, suggests that there are two primary positions as to how much influence ER can bring about to these effects. One standpoint views ER as the only contributor, where ER alone is considered to lead to the improvement in every language skill. One of the representative researchers taking this standpoint is Krashen (2004). He argues in his book that reading is "the only way we become good readers, develop a good writing style, and adequate vocabulary, advanced grammatical competence, and the only way we become good spellers (p. 37)." The word reading by Krashen refers to Free Voluntary Reading (FVR), which means that learners are free to choose the material they want to read and read voluntarily with no requirements. FVR also means that learners can put down a book they do not like and pick another one instead, and they do not need to look up every word even if they encounter unknown words. Using FVR in almost the same meaning as ER, he argues that FVR is the only learning way that has a significant ripple effect, bringing about a substantial outcome for learners.

On the other hand, some researchers take a different position from Krashen (2004). Even though they acknowledge the effectiveness of ER, they argue that ER alone is not sufficient to acquire every language skill. For example, Takeuchi (2007) suggests that ER serves as a necessary condition to enhance foreign language skills, but it is not a sufficient condition. Brown and Larson-Hall (2012, p. 54) state that "input alone does not lead to language acquisition." For the researchers in this position, something extra in addition to ER is considered necessary in order to gain greater effects. The examples of "something extra" which have been given so far are reading strategy (Shen, 2008; Susser \& Robb, 1990), intensive reading (Carrell \& Carson, 1997), intentional vocabulary learning (Furukawa, 2010), explicit grammar instruction (Furukawa, 2010; Shirahata, 2015), shadowing (Nakanishi \& Ueda, 2011), and output activities (Kanatani, 2005; Muranoi, 2006; Oi, Tabata \& Matsui, 2008; Tanaka, 2016).

The present paper takes the latter position with regard to the effects of ER and focuses on the output activities which help develop the learners' productive ability, on the basis of the consideration that the productive ability can be developed through the language use experience as Kanatani (2005), Oi et al. (2008) and Tanaka (2016) argue. Kanatani points out that ER alone does not necessarily connect to the success in improving English in every aspect. He then mentions the importance of using words or expressions encountered in the text so that some of them will be retained. Oi et al. discuss in their book that even if a large amount of language input is given and learners can understand it, it does not always mean that they can acquire it. They additionally point out that it is not until they use it that they realize the lack or gap in their knowledge. Tanaka argues that it seems difficult to acquire the extended usage of vocabulary and complex grammatical rules only through the implicit language exposure.

Concerning the benefits of ER on the development of productive ability, the learners' awareness is suggestive as well. Figure 1 illustrates the results of a questionnaire survey conducted to the students of the present paper $(n=46)$, who were 17-18 years old and had received 30-minute in-class ER per week about 30 times in total at the time of the survey. They were asked to answer whether they had felt the ER program contributed to the improvement of their listening, speaking, 
and writing ability, and reading fluency and vocabulary building. As the figure demonstrates, while more than half students regarded the ER program as beneficial in the improvement of reading fluency and vocabulary building, only $22-34 \%$ recognized the effectiveness of ER in the growth of listening, speaking, and writing. This result displays that at least some students were skeptical about the efficacy of ER on their productive ability development.

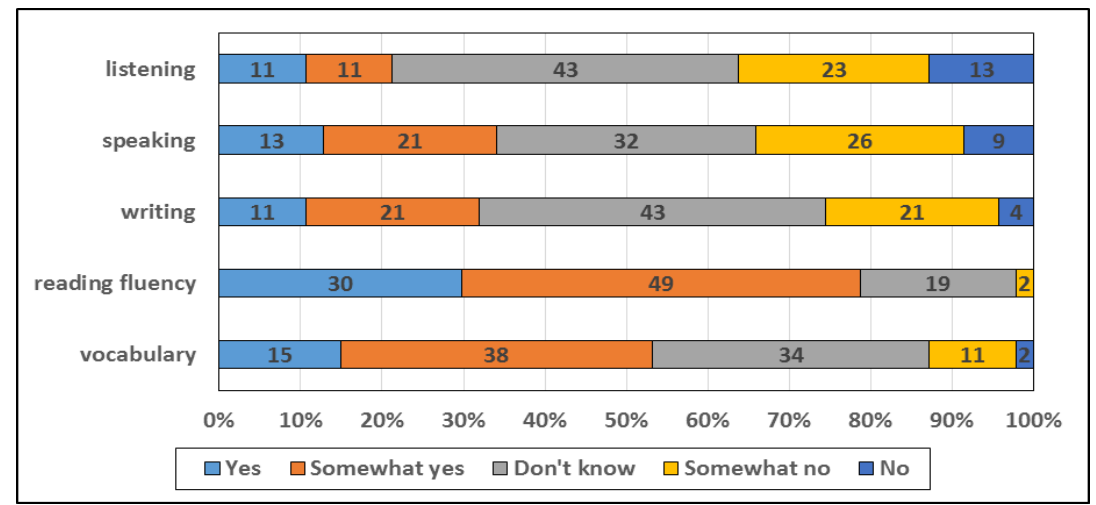

Figure 1. The recognition of ER effects in the L2 development

In spite of the arguments that the language use experience in addition to ER plays an essential role for the output ability development, little attention has been paid as to what type of activity can be served as an appropriate output exercise of ER and what effects it could bring about. The next section deals with the issue of a proper after-ER output activity, discussing its rationale.

\section{Mini-BIBLIOBATtLE AS AN OUTPUT ACTIVITY OF ER}

\section{A. The Rationale for an Output Activity of ER}

From the viewpoint of the link with ER, it seems that an appropriate output activity needs to meet at least the two conditions, i.e., continuity with ER and relatedness to ER (Fujii, 2017b). The continuity with ER can be interpreted in two ways, i.e., continuity from ER and continuity to ER. An appropriate output activity of ER should be intended for learners who have read a certain amount of English because the purpose of this exercise is to offer an opportunity to use English obtained through the ER program. As a rough indication, in the case of Japanese EFL learners, about 100,000 total words input would be desirable for conducting an output activity. This is because the number is regarded as a threshold for Japanese learners of English to realize the effect of ER (Takase, 2010) and to be able to read the beginning level of major graded reader series fluently such as Oxford Bookworms Library, Macmillan Readers, and Pearson English Readers. In the ESL (English as a Second Language) environment, graded readers play a fundamental role as the principal language resource in the ER course (e.g., Day \& Bamford, 1998). However, in general ER courses in Japan, besides graded readers, picture books, children's books and leveled readers, i.e., easy leveled books written for children of native English speakers, are also used. This has enabled learners at any proficiency level to start reading extensively without difficulties, which is one of the factors of spreading the ER program throughout Japan. These learners often begin with the Oxford Reading Tree series (Furukawa, 2010; Furukawa \& Kawade 2003; Sakai \& Kanda, 2005; Takase, 2010).

As for the condition of continuity, ER should be the premise to conduct the activity. Providing learners with an exercise to use English which they learned in a book will serve as an input-output connection. In addition, making learners expect a later output activity may promote the ER commitment. The continuity from ER thus plays an important role. The activity will be more effective if it motivates learners to read more enthusiastically after doing it. It is needless to say that this practice does not mean the end of the ER program. Learners need to keep reading in order to improve their English. In this respect, an output activity of ER should be the one which would bring out the learners' commitment to ER after the practice. Therefore, the continuity to ER is also crucial in considering an output exercise of ER.

The other word relatedness refers to the quality of English which will be used in the activity. It will be more reasonable if some of the words and expressions encountered in the ER program are used in the activity. For instance, in the case where graded readers and leveled readers that learners have read in the ER program serve as good material for the output activity, this will be an example which is related to the ER program in terms of the quality of English. If learners are supposed to use some expressions from a book, then the English input gained through ER will be more meaningful, authentic and personal to learners (Tanaka, 2016). Thus, continuity and relatedness seem to be the factors that need considering whether it is appropriate as an output activity of ER. Based upon the above discussions, the next section proposes the Mini-Bibliobattle, in which each participant makes a three-minute presentation and answers the questions by the audience in the following discussion period, as one of the appropriate and feasible output activities of ER. 


\section{B. Mini-bibliobattle}

According to Taniguchi (2013), the Bibliobattle has its root in a laboratory at Kyoto University in Japan in 2007. The term Bibliobattle was coined by Taniguchi, consisting of Biblio and battle. In other words, the Bibliobattle refers to a book-review battle. It has some original features the other book-review activities do not have. The general procedure of the Bibliobattle goes as follows: (a) Make a group of 4-6. (b) Each presenter, called bibliobattler, brings one favorite book that he or she wants to introduce to the other participants in a group. (c) Decide the order of presentation by, for example, playing rock-paper-scissors or drawing lots. There is no official rule as to how to decide the order. (d) Give a presentation on the book for 5 minutes for the battle. (e) After the initial five-minute presentation, the discussion period follows for 2-3 minutes, in which the other presenters may ask questions about the book reviewed. (f) After all the presentations completed, vote for the book which each participant would like to read the most by a show of hands. (g) The book which gets the most votes will be the champion book of the day or champu-bon in Japanese.

In the discussion period, questions like who the author is, why the presenter chose the book, or how long it took to read through the book are frequently asked, but basically, any questions can be asked as long as they are related to the book. Questions with a purpose of pulling presenter's leg are prohibited, and the warm and relaxed atmosphere where every presenter and audience can enjoy is welcomed. In deciding the champion book of the day, presenters are not supposed to vote for a book they introduced as implicit consent.

The Bibliobattle is unique in that the best presenter does not always receive the most votes because the standard for judging is not on the presenter but the book. Each voter is asked to vote for a book that he or she wants to read the most, and the appeal of the book as well as the quality of presentation is an essential factor in gathering many votes to be a champion book. This is why the winner of the battle is called champu-bon, the champion book of the day. It is not a person but a book that is awarded in this battle.

The Bibliobattle has another type, called Mini-Bibliobattle, in which each presenter gives a three-minute presentation, but the rest of procedure and rules is identical with the ones for the Bibliobattle. The Mini-Bibliobattle is intended for young participants who feel difficult to make a five-minute presentation (Bibriobattru Fukyu Iinkai, 2015). In a case study in the present paper, the Mini-Bibliobattle was employed, taking the learners' English proficiency level into consideration. The learners in this study were EFL Japanese learners at the elementary level based on their TOEIC ${ }^{\mathrm{R}}$ test score, and they had received only a few opportunities to make a presentation in English in front of the audience. From this situation, it seemed proper to start with a three-minute presentation and proceed to the higher step next time.

Concerning the appropriateness of the Mini-Bibliobattle as an output activity of ER, let us analyze this activity from the two conditions posited in Section 3, i.e., continuity with ER and relatedness to ER. If the books for the battle are limited to the ones read in the ER program, it will be necessary for learners to read many English books to choose which one they would like others to read. Furthermore, the Mini-Bibliobattle will also be a good opportunity to get to know new intriguing books reviewed by the other presenters, which can motivate them to read more after the battle. The Mini-Bibliobattle, therefore, can be said to meet the continuity condition in both ways, i.e., continuity from ER and continuity to ER. As for the relatedness to ER, preparation for presentation plays an important role. In writing a script for the presentation in the battle, learners can quote their favorite expressions or scenes in a book, or they may need to explain the outline of the story. In these cases, learners will refer to a book many times for their presentation, making the input-output relatedness possible. It is considered, therefore, that the Mini-Bibliobattle can serve as one of the valuable opportunities to use English gained through ER.

From a different point of view, by adding this battle to the ER program, learners may read English with more careful attention because they need to select one book for the battle, considering whether the story, readability and the punch line are good enough. If this is the case, the Mini-Bibliobattle will also be suitable for learners who have already had an ER experience for a long period and been stuck in a rut. This activity can make a change of pace and mood for such learners.

Then, one question comes up: What effects could the Mini-Bibliobattle bring to learners who have experienced the ER program? This issue needs to be examined from many aspects while accumulating lots of empirical research. In order to explore this big question, the present paper has set up the following two research questions and decided to conduct a case study:

(A) Do the learners' reading attitudes change after experiencing the Mini-Bibliobattle? If yes, how do they change?

(B) Do learners recognize that the Mini-Bibliobattle is a meaningful output activity of ER?

Reading attitudes in (A) focuses on the two aspects, i.e., how learners choose an English book and how learners read an English book. These two respects are regarded as significant viewpoints for teachers to lead to successful ER programs (Jenks \& Brinham, 2012; Nishizawa et al. 2010). Thus, suggestions obtained from the case study may bring significant educational implications.

\section{CASE STUdy}

\section{A. Participants}

A total of 46 students participated in this study. All the participants were in the third grade, aged 17 to 18 , at a technical college in Japan. Their major was engineering, and they had received formal English education for 
approximately 5 to 7 years at the time of the study. The participants had received about 30-minute in-class ER per week for two years, about 30 times in total, and had read 84,511 total words and 119 total books on average during that period. The average TOEIC Bridge ${ }^{\mathbb{R}}$ score was 134.9 , being at the elementary level or A1 to A2 level on the Common European Framework for Reference measures (IIBC).

\section{B. Practice of the Mini-bibliobattle}

The Mini-Bibliobattle was conducted two times, at the end of the spring semester in September and the end of the fall semester in February. In the Mini-Bibliobattle, the participants were divided into ten groups, each of which consisted of four or five students. In the first Mini-Bibliobattle, each participant chose a book for the battle from April to May, wrote an English script for the presentation from June to August and practiced reading the text aloud in September. About half of the preparation had been made at home as the assignment, and the other half had been made in a classroom in the form of group work. On the day of the Mini-Bibliobattle, each of them brought a favorite book for the presentation, made a three-minute presentation and carried through a two-minute discussion period. When all the sessions completed, a champion book was selected in each group, and ten champion books were decided in a class.

After the first Mini-Bibliobattle was completed, the author attached a sticker on the front cover of all the champion books to show they were selected as a champion. Further, the author made a poster of the champion books, displayed it and made a "champion book corner" in the school library gathering all the champion books in one place. These are meant for more active participation in ER after the battle.

For the second Mini-Bibliobattle, the participants were instructed to choose a different book from the spring semester and were encouraged to make a better presentation with a better script, making eye contact with the audience based on firm memorization of the script. They wrote an English script and practiced reading it aloud from December to February. Most of the preparation this time had been made at home as the assignment.

\section{Questionnaire}

In order to explore the research questions, a questionnaire survey was created. This survey consisted of the four categories: (1) How do learners recognize the effectiveness of ER (the same question items as in Figure 1)? (2) How do learners choose English books? (3) How do learners read English books? (4) How much do learners recognize the meaningfulness of the Mini-Bibliobattle as an output activity of ER? Five questions were provided for the category (1), ten questions for the category (2), seven questions for the category (3) and four questions for the category (4), making up of 26 questions in total in the questionnaire. The 5-point Likert scale was employed for each question. The questions in the categories (2) and (3) are for exploring the research question (A), and the questions in the categories (1) and (4) are for the research question (B).

In the questionnaire survey in April, four questions in the category (4) were not asked. In the investigations in September and February, all questions were asked.

\section{Procedure and Analysis}

The study was conducted from April 2016 to February 2017 and consisted of the three stages. The first stage is the beginning of the spring semester in April, the second stage is the end of the spring semester in September, when the Mini-Bibliobattle was conducted for the first time, and the third stage is the end of the fall semester in February, when the Mini-Bibliobattle was performed for the second time.

First, a questionnaire survey excluding the four questions in the category (4) was conducted to the participants at the very beginning of the spring semester in April. This was to examine the participants' reading attitudes until the end of the preceding academic year.

Second, the same questionnaire survey was used at the end of the spring semester in September after conducting the Mini-Bibliobattle for the first time. This was to investigate how the participants' reading attitudes would change from April by incorporating the Mini-Bibliobattle into the ER program and experiencing the output activity.

Third, the same questionnaire survey was conducted at the end of the fall semester in February after the MiniBibliobattle for the second time. This was to explore the change of the participants' reading attitudes from April and September by experiencing the Mini-Bibliobattle two times.

In a regular English class from April to September in the spring semester and from October to February in the fall semester, the in-class ER program was conducted for approximately 30 minutes per week. As a result, the total accumulative number of words read by the participants reached 159,406, and the total accumulative number of books read reached 155 on average at the end of the fall semester in February. The rest part of the class was used mainly for the intensive reading course using a textbook, vocabulary learning, and grammar instruction. A few hours were spent on the preparation for the Mini-Bibliobattle. Table I shows the brief procedure of this study. 
TABLE I

THE STUDY DESIGN

\begin{tabular}{l|l|l}
\hline Month & What was done in class \\
\hline \hline April & Questionnaire survey & \multicolumn{1}{|c}{$\mid$} \\
& & $\begin{array}{l}\text { 30-minute in-class ER per week } \\
\text { Intensive reading course } \\
\text { Vocabulary and grammar instruction }\end{array}$ \\
\hline September & $\begin{array}{l}\text { Mini-Bibliobattle } \\
\text { Questionnaire survey }\end{array}$ & $\begin{array}{l}\text { 30-minute in-class ER per week } \\
\text { Intensive reading course } \\
\text { Vocabulary and grammar instruction }\end{array}$ \\
\hline February & $\downarrow$ & \\
& $\begin{array}{l}\text { Mini-Bibliobattle } \\
\text { Questionnaire survey }\end{array}$ & \\
\hline
\end{tabular}

With regard to the analysis, the descriptive statistics of the questionnaire surveys were calculated. Then, one-way analysis of variance (ANOVA) was performed to analyze the statistical difference of the three questionnaire survey results in the categories (1), (2) and (3). In the case where the significant difference was detected, Bonferroni's multiple comparison tests were conducted. As for the analysis of the statistical difference of the results in the category (4), paired t-test was carried out. The alpha level was set at .05 for both of the tests.

\section{RESULTS AND DisCUSSIONS}

Table II illustrates the descriptive statistics of the results of the three questionnaire surveys. The question items, the mean value of responses to each question in April, September and February, and the results of ANOVAs, multiple comparison tests and t-tests are displayed for each category in the table below:

TABLE II

DESCRIPTIVE STATISTICS OF THE QUESTIONNAIRE SURVEY

\begin{tabular}{|c|c|c|c|c|}
\hline Questions & Apr. & Sep. & Feb. & \\
\hline I think ER is effective in building vocabulary & 3.53 & 3.64 & 3.90 & \\
\hline I think ER is effective in the reading fluency development & 4.06 & 4.00 & 4.19 & \\
\hline I think ER is effective in the improvement of speaking ability & 3.13 & 3.28 & 3.69 & \\
\hline I think ER is effective in the improvement of writing ability & 3.04 & 3.22 & 3.57 & $*$ Feb.>Apr. $=$ Sep. \\
\hline I think ER is effective in the improvement of listening ability & 2.83 & 2.85 & 3.21 & \\
\hline I choose a book from my favorite genres (e.g., suspense, romance, etc.) & 3.09 & 3.57 & 3.93 & *Feb.>Apr. \\
\hline I choose a book from various genres (e.g., suspense, romance, etc.) & 2.77 & 3.17 & 3.55 & *Feb.>Apr. \\
\hline I choose a book with large word counts & 3.55 & 3.65 & 3.64 & \\
\hline I try to read as many books as I can & 3.13 & 3.07 & 3.55 & *Feb.>Sep. \\
\hline I choose a book from my favorite series. (e.g., Oxford Reading Tree, Macmillan Readers, etc.) & 3.39 & 3.93 & 3.76 & \\
\hline I choose a book from various series (e.g., Oxford Reading Tree, Macmillan Readers, etc.) & 2.49 & 2.78 & 3.45 & *Feb.>Apr.=Sep \\
\hline I choose a book with small word counts & 2.19 & 2.15 & 2.71 & $*$ Feb. $>$ Apr. $=$ Sep \\
\hline I choose a book which I can understand more than $70 \%$ & 3.85 & 3.76 & 4.05 & \\
\hline I choose a book which I can read fluently & 3.04 & 3.02 & 3.48 & \\
\hline I skip unknown words or expressions without guessing the meaning. & 2.91 & 2.85 & 3.24 & \\
\hline I guess unknown words or expressions while reading & 4.07 & 3.93 & 4.00 & \\
\hline I repeatedly read to guess the meaning when encountering unknown words or expressions & 2.81 & 2.96 & 3.38 & *Feb.>Apr.=Sep \\
\hline I look up unknown words or expressions in a dictionary after reading & 2.13 & 2.35 & 2.83 & $*$ Feb.>Apr.=Sep \\
\hline I do not care if I skip unknown words or expressions & 2.98 & 3.11 & 3.31 & \\
\hline I try to memorize favorite words or expressions I found in a book & 2.66 & 2.91 & 3.31 & *Feb.>Apr.=Sep \\
\hline I try to use favorite words or expressions I found in a book when writing or speaking English & 2.60 & 2.53 & 3.12 & *Feb.>Apr.=Sep \\
\hline It was fun for me to do the Mini-Bibliobattle & $\sqrt{2}$ & 3.76 & 4.00 & $* t(39)=2.51$ \\
\hline I feel English used in the Mini-Bibliobattle was personal and original & 1 & 4.18 & 4.17 & \\
\hline I want to read books introduced by other students & 2 & 3.83 & 4.10 & $* t(41)=3.32$ \\
\hline I think the Mini-Bibliobattle is a meaningful output activity of ER & 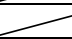 & 4.07 & 4.24 & \\
\hline
\end{tabular}

The significant difference was found in twelve questions, and the mean value all increased from April or September to February. In the category (1), for example, the results of ANOVA and the multiple comparison tests demonstrate that the participants have a stronger tendency in February than in April or September to think that ER is effective in the improvement of writing ability. Likewise, five questions in the category (2) (e.g., I choose a book from my favorite genres), four questions in the category (3) (e.g., I repeatedly read to guess the meaning when encountering unknown words or expressions) and two questions in the category (4) (e.g., It was fun for me to do the Mini-Bibliobattle) statistically show the significant difference among the results of April, September, and February.

From these results, several findings are obtained. First, the results in the category (1) show that the participants found ER would help build their writing ability by experiencing an opportunity to write an English script in preparing for the Mini-Bibliobattle. Then why was a significant change observed in writing but not in speaking? One possible interpretation would be the difference in the participants' learning experience between writing and speaking. According 
to a survey result in April, only 15\% of the participants answered that they had had an experience of writing more than 300 words in English. For the presentation, they prepared a script with about 300-word length, which means that it was a new experience for the $85 \%$ students. On the other hand, approximately $30 \%$ of the participants had already had an experience of making a speech or presentation in front of other students before the Mini-Bibliobattle. This prior language use experience may lead to the difference in the impact on the participants. It should be noted, however, that the mean value in recognition of ER effects in the speaking ability development also increased from April to September and to February, leading to a significant difference at the .10 alpha level. From these results, it is suggested that the recognition of ER effects would be extended to the writing ability development by providing an output activity to use the resource gained through ER.

Second, a significant difference was detected in four questions in the category (2). These results show a stronger tendency in February that the participants were picking up a book from various genres and series of the ER library while placing their favorite one in the center. Two potential explanations are considered for this change. The first discussion would be that through experiencing the Mini-Bibliobattle, the participants found many exciting genres and series they had not known before. The data in the category (4) which represents the stronger interest turned to others' books in February confirms this interpretation. The experience of the Mini-Bibliobattle may have led them to pick a book from more diverse genres or series than before and helped convince them what genres they really like. The second discussion would be that they merely needed to find an intriguing book for the Mini-Bibliobattle from as many books as possible. This would also lead to a reason why more students in February tried to read as many books as possible and chose a book with small word counts. From these results and discussions, it can be suggested that incorporating the Mini-Bibliobattle into the ER program can expand the range of book selection. As Day (2015) states, "when students read a wide range of reading material, they learn a flexible approach to reading (p. 11)."

Third, the statistical analyses detected a significant difference in four questions in the category (3). In consideration of these results, the suggestions would be that the participants may read English more carefully and intensively by incorporating the Mini-Bibliobattle into the ER program and that they may strengthen a tendency of careful reading by experiencing the Mini-Bibliobattle. One plausible interpretation for this change would be that the participants were more or less aware while reading that they would need to tell in the Mini-Bibliobattle how intriguing the book is by referring to the text as necessary. This awareness may have caused a change in their way of reading to more careful and output-oriented. Furthermore, this recognition also may have led them to read the text many times or to use a dictionary to ensure the understanding.

Fourth, from the results of four questions in the category (4), the values were overall high enough to regard the MiniBibliobattle as a fun and meaningful activity for the participants. In particular, about $80 \%$ of them in September and about $90 \%$ of them in February recognized that the Mini-Bibliobattle was a meaningful output activity of ER. It is also shown that the participants' evaluation of the Mini-Bibliobattle overall got higher from September, which has led to a significant statistical difference in two items. One possible justification for these results would be that doing the same activity for the second time enabled them to make a more satisfactory performance and give them a bit of breathing room in their heart to enjoy it.

Some pedagogical implications are obtained through the suggestions from the present case study. For one thing, the Mini-Bibliobattle would be particularly proper for those who have had an ER experience for a certain period of time because it provides learners with an opportunity to use English in an ER book. The Mini-Bibliobattle would also be appropriate for those who have been stuck in a rut in ER and need some change of reading pace because it can expand the range of book selection and change the way of reading more careful and output-oriented. The second pedagogical implication would be that the Mini-Bibliobattle can be recognized by most learners as a meaningful activity to bridge between input and output. With the theoretical background argued in Section III, the Mini-Bibliobattle can be proposed as one of an appropriate output activity both theoretically and empirically.

\section{CONCLUSION}

Preceding studies have suggested that the language use experience is necessary to extend the effectiveness of ER to the development of the output ability. Until now, however, there has been little study done concerning what output activity is appropriate and what effects can be brought about by conducting it. This paper proposed the MiniBibliobattle as a suitable output activity of ER, discussing its rationale from the two perspectives, i.e., continuity with ER and the relevance to ER. Then the Mini-Bibliobattle was conducted two times with 46 third-year EFL students at a technical college, who had experienced ER for two years. The effects of the Mini-Bibliobattle were investigated focusing on the change in their way of reading through the three questionnaire surveys. Specifically, the two research questions were explored: (A) Do the learners' reading attitudes change after experiencing the Mini-Bibliobattle? If yes, how do they change? (B) Do learners recognize that the Mini-Bibliobattle is a meaningful output activity of ER?

The findings drawn from the statistically analyzed results of the present case study confirm the answers. The answer to the research question (A) is yes. The participants strengthened a tendency of reading English more carefully and intensively and expanding the range of book selection. The answer to the research question (B) is for most learners, yes. This result ensures the appropriateness of the Mini-Bibliobattle as an output activity of ER not only theoretically but also from empirically. 
The limitations of this study also need to be acknowledged for further investigation. First, the present case study displayed the results of the limited number of EFL participants at the elementary level. The results might have been different if the participants had been different. Therefore, the discussions and suggestions must not be treated as grim reality. It goes without saying that more follow-up studies are required for more reliable and multilateral suggestions. Second, a problem has remained unsolved concerning the decrease of the amount of English input because some period of time needs to be devoted to the Mini-Bibliobattle preparation if targeting learners at the elementary level. Further studies are required concerning at what stage the Mini-Bibliobattle should be incorporated into the ER program. Finally, the present case study did not deal with the effects of the Mini-Bibliobattle in terms of the standardized proficiency test score. Issues with regard to how this output activity can help develop the productive ability need to be investigated based on the objective scores as well.

However, this study despite its limitations contributed to widening the horizon of the output activity of the ER program by suggesting the Mini-Bibliobattle as an appropriate output activity both theoretically and empirically. It is hoped that the outcome of the present study will contribute to a better form of ER.

\section{ACKNOWLEDGMENTS}

This work was supported in part by a grant from National Institute of Technology, Center for International Exchange in Japan.

\section{REFERENCES}

[1] Bamford, J. \& R. R. Day. (2004). Extensive reading activities for teaching language. Cambridge: Cambridge University Press.

[2] Beglar, D. \& A. Hunt. (2014). Pleasure reading and reading rate gains. Reading in a Foreign Language 26.1, 29-48.

[3] Bibriobatoru Fukyu linkai. (2015). Bibriobatoru Handobukku [The handbook of the Bibliobattle]. Tokyo: Kodomo No Miraisha Publishing.

[4] Brown, S. \& J. Larson-Hall. (2012). Second language acquisition myths: Applying second language research to classroom teaching. Michigan: The University of Michigan Press.

[5] Carrell, P. L. \& J. G. Carson. (1997). Extensive reading in an EAP setting. English for Specific Purposes 16.1, 47-60.

[6] Day, R. (2015). Extensive reading: The background. Extensive Reading. Oxford: Oxford University Press.

[7] Day, R. \& J. Bamford. (1998). Extensive reading in the second language classroom. New York: Cambridge University Press.

[8] Fujii, K. (2013). Gakushukeitai ni motozuku ichinenkan no tadokujyugyou ga dokkaijyouimen to gaibusikenkekka ni ataeta eikyou [Effects of 1-year English extensive reading class on the reading consciousness and the results of TOEIC]. Journal of the Chubu English Language Education Society 42, 197-202.

[9] Fujii, K. (2017a). Jyugyounai tadoku ni yoru eibund okkai sokudo no henka nit suite [Effects of in-class extensive reading on reading fluency development]. Journal of the Chubu English Language Education Society 46, 247-252.

[10] Fujii, K. (2017b). The Mini-Bibliobattle as an output activity of extensive reading: The rationale and procedures. Journal of the Council of College English Teachers 36, 77-86.

[11] Fujita, K. \& T. Noro. (2009). The effects of 10-minute extensive reading on the reading speed, comprehension and motivation of Japanese high school EFL learners. Annual Review of English Language Education in Japan 20, 21-30.

[12] Furukawa, A. (2010). Eigo tadoku hou [The English extensive reading method]. Tokyo: Shogakukan Inc.

[13] Furukawa, A. \& M. Kawade. (2003). Ippai yomeba shikkari mini tsuku kyou kara yomimasu eigo 100 mango! [You can improve your English if you read a lot: Start reading one million words today!] Tokyo: Nippon Jitsugoyu Publishing.

[14] Grabe, W. \& F. L. Stoller. (2002). Teaching and researching reading. London: Longman.

[15] Green, C. (2005). Integrating extensive reading in the task-based curriculum. ELT Journal 59, 306-311.

[16] Horst, M. (2005). Learning L2 vocabulary through extensive reading: Measurement study. Canadian Modern Language Review $61.3,355-382$.

[17] IIBC. (no date). http://www.iibc-global.org/toeic/test/bridge/about/result.html (accessed 5/1/2018).

[18] Imamura, K. (2008). The effects of extensive reading for Japanese high school students on their reading and listening abilities, vocabulary and grammar. Annual Review of English Language Education in Japan 19, 11-20.

[19] Iwahori, Y. (2008). Developing reading fluency: A study of extensive reading in EFL. Reading in a Foreign Language 20.1, 70-91.

[20] Jenks, D. \& A. D. Brinham. (2012). The effects of text selection on student attitudes toward extensive reading. The Journal of Kanda University of International Studies 24, 181-202.

[21] Kanatani, K. (2005). Ishogashii hito no tadoku toreining menyu [The English extensive reading menu for busy people]. Tokyo: IBC Publishing.

[22] Krashen, S. (2004). The power of reading: Insights from the research. Connecticut: Libraries Unlimited.

[23] Kweon, S.-O. \& H.-R. Kim. (2008). Beyond raw frequency: Incidental vocabulary acquisition in extensive reading. Reading in a Foreign Language 20.2, 191-215.

[24] Muranoi, H. (2006). Daini gengo shutoku kenkyu kara mita koukateki na eigogakushu shidou hou [Effective ways of English teaching and learning from the second language acquisition research]. Tokyo: Taishukan Publishing.

[25] Nakamori, T. (2013). Gaikokugo wa dokoni kioku sareruka [Where is language stored?]. Tokyo: Kaitakusha Publishing.

[26] Nakanishi, T. (2005). A book in question! Interviewing receptive and productive skills using graded readers. The Language Teacher 29.6, 35-36.

[27] Nakanishi, T. \& A. Ueda. (2011). Extensive reading and the effects of shadowing. Reading in a Foreign Language 23.1, 1-16.

[28] Nation, P. (1997). The language learning benefits of extensive reading. The Language Teacher, 21.5, 13-16.

[29] Nation, I. S. P. (2001). Learning vocabulary in another language. Cambridge: Cambridge University Press. 
[30] Nation, P. \& R. Robb. (2013). Extensive reading and graded readers. Seoul: Compass Publishing.

[31] Nishizawa, H. (2010). Toyota kousen eigo kyouiku no tokutyou: Eigo taiken to shiteno koukan ryuugaku to tadoku jyugyou [The strength of English education at Toyota College: Studying abroad and the extensive reading program]. Journal of the Japan Association for Colleges of Technology 15.2, 9-14.

[32] Nishizawa, H., T. Yoshioka \& M. Fukada. (2010). The impact of a 4-year extensive reading Program. JALT 2009 Conference Proceeding, 632-640.

[33] Oi, K., M. Tabata \& T. Matsui. (2008). Paragurafu raityingu shidou nyumon [The introduction to paragraph writing]. Tokyo: Taishukan Publishing.

[34] Pitts, M., H. White \& S. Krashen. (1989). Acquiring second language through reading: A replication of the clockwork orange study using second language acquires. Reading in a Foreign Language 5.2, 271-275.

[35] Robb, T. N. \& B. Susser. (1989). Extensive reading vs skills building in an EFL context. Reading in a Foreign Language 5.2, 239-251.

[36] Sakai, K. (2002). Kaidoku hyakumango: peipabakku he no michi [Reading one million words: A road to paperback books]. Tokyo: Chikuma Library.

[37] Sakai, K. \& M. Kanda. (2005). Kyoushitsu de yomu eigo 100 mango [Read one million words in a classroom]. Tokyo: Taishukan.

[38] Shirahata, T. (2015). Eigo shidou ni okeru koukateki na ayamari teisei [Effective error corrections in English instruction]. Tokyo: Taishukan.

[39] Shen, M.-Y. (2008). EFL learners' responses to extensive reading: Survey and pedagogical applications. The Reading Matrix $8.2,111-123$

[40] Susser, B. \& T. N. Robb. (1990). EFL extensive reading instruction: Research and procedure. JALT Journal 12.2, 161-185.

[41] Takase, A. (2010). Eigo tadoku tachou shidou manyuaru [Instruction manual for English extensive reading and extensive listening]. Tokyo: Taishukan Publishing.

[42] Takase, A. (2012). The effectiveness of sustained silent reading in becoming autonomous learners. Gaikokugo Kyoiku Forum 11, 1-14.

[43] Takeuchi, O. (2007). Tatsujin no eigo gakushu hou [The way of English learning by English masters]. Tokyo: Soushisha Publishing.

[44] Tanaka, S. (2016). Eigo wo tsukaikonasu tameno jissennteki gakushuuhou [A practical way of learning English to use English]. Tokyo: Taishukan Publishing.

[45] Tanaka, S. \& H. Abe (1984). Conditions on interlingual semantic transfer. TESOL '84: A Brave New World for TESOL, 101120.

[46] Taniguchi, T. (2013). Biburiobatoru [Bibliobattle]. Tokyo: Bugeishunjyu Ltd.

[47] Waring, R. \& M. Takaki. (2003). At what rate do learners learn and retain new vocabulary from reading a graded reader? Reading in a Foreign Language 15.2, 130-163.

Kazuma Fujii received his M.A. in English literature from Doshisha University, Japan, in 2002 and his Ph.D. in Media and Governance from Keio University, Japan, in 2017. He is currently an associate professor at Nagaoka University of Technology in Japan. His main research interest lies in the effects and practice of extensive reading and the interface between cognitive linguistics and English teaching. Some of his papers have been published in Journal of Pan-Pacific Association of Applied Linguistics and English Language Teaching. 